\title{
Structural Damage Detection of A Steel-Truss Railway Bridge Using its Dynamic Characteristics
}

\author{
T. Susanto and A. Budipriyanto
}

\begin{abstract}
Many steel truss rail bridges in Indonesia were built decades ago. To assure that bridge structure is in-service conditions, periodic monitoring is required, thus structural health of the bridge can be assessed and sudden collapse of the structure can be avoided. In health monitoring of structure, structural damage detection methods are frequently required so that damaged/weak element of the structure can be identified and technique for repairing it can be determined. In this paper, structural damage detection method of steel truss bridge is discussed. The method applied in this study used vibration characteristics of the structure for detecting structural damages occurred in the structure. The method was utilized to identify simulated damages occurred in a steel-truss railway bridge located in Porong East Java. The bridge has span of 30 meters and it was built during the era of Dutch colonization. The structure was modeled numerically utilizing CSI Bridge v15 computer software for facilitating in obtaining its dynamic characteristics. Results of this study showed that the method could identify precisely the existence of damage took place in the structure.
\end{abstract}

Keywords — Dynamic Characteristics of Structure, Damage Detection, Steel-Truss Railway Bridge.

\section{INTRODUCTION}

Tndonesia as an archipelagic country has a unique topography that consist of lands and waters; there are rivers and sea strait in the country. This condition requires infrastructure such as bridges as an indispensable element of transportation.

Based on data from the Ministry of Public Works, Indonesia has more than 88,000 bridges or equivalent with length more than $1000 \mathrm{~km}$. Several of the bridges were built during the era of Dutch colonization. These include steel truss bridges of several types.

Because the bridge has been built for decades the bridges require special attention, especially in the maintenance phase. To assure that bridge structure is inservice conditions, periodic monitoring is required, thus structural health of the bridge can be assessed and sudden collapse of the structure can be avoided. Visual inspection of the bridge is part of the steel truss bridge maintenance process in Indonesia [1].

The types of inspection include inspection inventory, detailed inspection, and special inspection. Examination inventory is a collection of administrative data, geometry, material, and other additional data on each bridge, including the location of the bridge, span length, and type of construction for each span. Detailed examination is to record all of the bridge elements damage, and marked with a condition value for each element, group elements and the main components of the bridge. Special inspection is usually recommended by inspectors during detail inspection because inspector feels the lack of data, experience or expertise to determine the condition of the bridge.

In addition to visual inspection, one method of nondestructive evaluation of structures that are being developed is the structural damage identification based on dynamic characteristics. Through the calculation of

${ }^{1}$ T. Susanto and A. Budipriyanto are with Departement of Civil Engineering, Faculty of Civil Engineering and Planning, Institut Teknologi Sepuluh Nopember, Surabaya, 60111, Indonesia. E-mail: tri3soe@yahoo.com; agungbp@ce.its.ac.id. dynamic characteristics of damaged structural elements, the damage of the structure can be identified. The method was utilized to identify simulated damages occurred in a steel-truss railway bridge located in Porong East Java. The bridge has span of 30 meters and it was built since the era of colonization.

\section{A. Structural Damage Detection Study}

Detection of structural damage can be divided into several categories and methods as depicted in Table 1 [2]. Natural frequency can be used as a parameter in the diagnosis of vibration-based structural feasibility.

This approach is based on the fact that the natural frequency is a sensitive indicator in the system affect the unity of a structure [3]. However, the method using only the natural frequency of the damage analysis has limitations. This is because the frequency changes can occur due to damage at the same position or a different area [4]. Significant damage only causes a little change in natural frequency. Therefore, a small change in frequency is to be neglected, due to the correction in the measurement. Besides the natural frequency changes can not differentiate damage to the symmetrical location [5]. So by comparing the mode shapes of vibration it will provide a better measurement of the placement location of damage [6]. Against this backdrop, this study will try to identify structural damage with combined capital of the two parameters, that is the natural frequencies and mode shapes. However, damage detection based on measurement of natural frequencies and mode shapes that ignoring damping, has limitations because it is considered to have a low sensitivity [7].

Analysis of structural damage on the bridge can be performed using indicator the changes in curvature on a variety of mode shape [8]. Lanczos algorithm can be used to get more accurate modal parameters and the damage is identified by changes in the natural frequency and the derivative of the function of mode shape [9]. Numerical studies to detect structural damage can also be done with the use of rotational changes in mode shapes [10]. This study can show the relationship between the damage characteristics and the change of dynamic property. Rotational mode shapes is a sensitive indicator 
of damage that can indicate the location of the area of damage but cannot indicate displacement. Rotational mode shapes are very powerful in determining the location of the damage, including the structures with different sizes.

In [11] a method using response surface metamodel (RSM) was presented. This method was reported to be able to successfully identify the structural damage for linear and non-linear systems. The author mentioned that one of the advantages of RSM was that it requires only very little information about the system to relate damage indicators and system response.

There was also method based on artificial neural network with consideration of errors in baseline finite element method [12]. Existence of differences ratio in the mode shapes before and after the damaged structure were used as inputs in the neural network method. The authors stated that this method was effective to be applied either by numerical analysis and laboratory tests.

Methods using the acceleration response data were presented in [13-15]. These methods related the acceleration responses of the frequency response function (FRF) with the mode shapes. Change of energy and change of curvature could be used to detect damage. However, the use of the change of curvature was seemed to be better than a change of energy. The authors claimed that these methods capable of showing the damage location and capable of detecting the amount of damage.

Identification of structural damage using dynamic modal data (mode shapes and frequencies) was conducted by comparing the effectiveness of the method of changes in mode shapes and frequencies, the flexibility, changes of the curvature mode shapes, and method of the FRF curvature [4]. The study reported that the FRF curvature method was capable of identifying damage locations and the value of the level of damage to all of the tested beams.

The application of the finite element method with the conventional Ritz method for damage detection was reported in [16]. Singular value decomposition technique was used to obtain an index of damage. The index was reported to be sensitive to changes in the dynamic characteristics due to the damage. The results of numerical study showed that the location and extent of damage scenario could be detected using the method [16].

Global Filtering Method (GFM) based deflection curvature shape of the dynamic response of passing vehicles was employed in [17]. This method used the information of damage and verified by numerical simulation experiments. This method utilized the deflection shape curvature. It was reported that the method was able to detect damage in numerical simulation and experimental study. The authors noted that the method would give greater accuracy and not require a lot of sensors if it was combined with data obtained from the frequency response function (FRF) [17].

In this study dynamic characteristics of undamaged and damaged steel railway bridge under train passage were investigated. Damage was simulated by reducing the cross sectional area of the bridge structural element. Natural frequency and spectrum of the bridge were investigated to distinguish the bridge conditions, i.e. healthy (undamaged) and damage conditions.

\section{METHOD}

\section{A. Equation of Motion}

For structure under dynamic loads, the equation of motion can be written as [20]:

$$
\ddot{y}(t)+2 \zeta \omega \dot{y}(t)+\omega^{2} y(t)=f(t)
$$

Where $y(t)$ is the displacement, $\dot{y}(t)$ is velocity, and $\ddot{y}(t)$ is acceleration. $f(t)$ is input of motion. The pseudo-acceleration spectrum and the total acceleration spectrum can be related as:

$$
\begin{aligned}
& \ddot{f}(t)_{T}=\ddot{y}(t)+\ddot{f}(t) \\
& \ddot{f}(t)_{T}=-\omega^{2} y(t)-2 \zeta \omega \dot{y}(t)
\end{aligned}
$$

For very small damping, the second formula in equation (3) can be neglected. Therefore the acceleration spectra can be expressed as:

$$
\mathrm{S}(\omega)=\omega^{2} y(t)
$$

The $S(\omega)$ is used for damage identification in this study.

\section{B. Structural Damage Modeling}

Generally, structural damage can resulted in the reducing of stiffness in a structural system at certain locations. This may affect dynamic characteristics of the system. Modeling of damage can be made by changing mass and inertia of an element [18]. To get the modal parameter mode shapes, natural frequencies, and the results of time history analysis, the modeling of undamaged and damaged structural will be using CSI BRIDGE V15 software. The spectra of the bridge under damage and undamaged were also calculated and compared.

Data collection is performed by obtaining as-built drawings and material properties from PT. Kereta Api Indonesia (Persero), DAOP 8, Surabaya. In addition it is also necessary to obtain a sketch of the location of corrosion fit the reality. In this study are the analysis is performed when (a) Passing train speed is fixed, (b) Train load used is CC201 locomotive type and modeled as vehicle load [19], (c) Material properties used are Fe510C steel with $\mathrm{Fy}=355 \mathrm{MPa}$ and $\mathrm{Fu}=490 \mathrm{MPa}$ [19], (d) Type of mode is the Ritz Vector with Bridge Live Load Type (e) Structural damage was simulated by reducing the cross-sectional area at the corroded section accordance with reality.

\section{RESULT AND DISCUSSION}

Damping ratio used was 5\%. And the damage is simulated by a reduction in cross-sectional area by $10 \%$. Modeling with CSI BRIDGE V15 is presented in Figure 3 . Figure 4 shows the location of simulated. From the analysis of the natural frequencies can be seen in table 2 . Although the changes of natural frequency can indicate the presence of damage but the analysis cannot indicate the location of the damage between un-damaged model 
and damaged model. To find the damage location, need to find the relationship between the natural frequency and pseudo spectral accelerations (PSA). Analyzes were performed at node points along the bridge. The results of the analysis can be seen in figure 5-9.

\section{CONCLUSION}

From this study it can be concluded that the structural damage detection based on the dynamic characteristic by application of changes of natural frequency and spectral response were able to show the location of the potential damage. The most potentially damaged location is the section closest to the middle of bridge span and the closest to the location of corrosion.

In this paper the damage was only simulated with a single location, further studies will be conducted to analyze the effects of multiple damages. Different values of damping will also be investigated.

\section{ACKNOWLEDGEMENT}

Our thanks to Mr.Sugiono and Mr.Sulandi from PT. Kereta Api Indonesia (Persero), Daop 8 Surabaya, who has given a lot of information to the completion of this paper.

\section{REFERENCES}

[1]. Anonym, "Indonesian Guidelines for Building Construction Number 005/BM/2009”, Ministry of Public Works Directorate General of Highways, 2009

[2]. Lee, J. J. Lee, J. W. Yi, J. H. Yun, Bang, C. Jung, H. Y, “Neural Networks-Based Damage Detection for Bridges Considering Errors in Baseline Finite Element Models”, Journal of Sound and Vibration, 280 555-578, 2004

[3]. Salawu, O. S, "Detection of Structural Damage Through Changes in Frequency: a review”, Engineering Structures, Vol. 190, No. 9, pp. 718-72, 1997

[4]. Musbar, "Identifikasi Kerusakan Struktur Balok Dengan Menggunakan Analisis Data Modal Dinamik”, Tesis Program Studi Magister Teknik Sipil Institut Teknologi Bandung, 2007

[5]. Kim, J. Ryu, Y. Cho, H. Stubbs, N,’Damage Idenfification in Beamtype Structures: Frequency-based Method vs. Modeshapes-based method”. Engineering Structures, 25(1):57-67, 2002
[6]. Salawu, O. S, "Structural Damage Detection using Experimental Modal Analysis", Proc. Of the 11th International Modal Analysis Conference, Kissimmee, Florida, 254-260, 1993

[7]. Curadelli, R.O. Riera, J.D. Ambrosini, D. Amani, M.G, "Damage Detection by Means of Structural Damping Identification”, Engineering Structures, 30 3497-3504, 2008

[8]. Wahab, M. M. A. Roeck, G. De, "Damage Detection in Bridges Using Modal Curvatures: Application to A Real Damage Scenario”, Journal of Sound and Vibration, 226(2), 217-235, 1999

[9]. Dutta, A. Talukdar, S, "Damage Detection in Bridges Using Accurate Modal Parameters”, Finite Elements in Analysis and Design, 40 287-304, 2002

[10]. Abdo, M. A. B. Hori, M, "A Numerical Study of Structural Damage Detection Using Changes in The Rotation of Mode Shapes”, Journal of Sound and Vibration, 251(2), 227-239, 2002

[11]. Cundy, A.L, "Use of Response Surface Metamodels in Damage Identification of Dynamic Structures”, Thesis, Master of Science in Engineering Science and Mechanics, Los Alamos National Laboratory, Blacksburg, Virginia, 2003

[12]. Lee, L. S. Karbhari, V. M. Sikorsky, C, "Investigation of Integrity and Effectiveness of RC Bridge Deck Rehabilitation with CFRP Composites”, Department of Structural Engineering, University of California, San Diego, SSRP-2004/08, 2004

[13]. Dong, Z. X. Wu, Z, "Energy Damage Detection Strategy Based on Acceleration Responses for Long-Span Bridge Structures", Engineering Structures, 2006

[14]. Kimsan, M, "Identifikasi Kerusakan Struktur Portal 2 Dimensi Dengan Metode Frequency Respons Function (FRF)”, Tesis Program Studi Magister Teknik Sipil, Institut Teknologi Bandung, 2009

[15]. Huang, Q. Xu, Y. L. Li, J.C. Su, Z.Q. Liu, H.J, "Structural Damage Detection ff Controlled Building Structures Using Frequency Response Functions”, Journal of Sound and Vibration, 331 3476-3492, 2012

[16]. Gharighoran, A. Daneshjoo, F. Khaji, N, "Use of Ritz Method for Damage Detection of Reinforced and Post-Tensioned Concrete Beams", Construction and Building Materials, 23 2167-2176, 2008

[17]. Zhang, Y. Lie, S. T. Xiang, Z, "Damage Detection Method Based on Operating Deflection Shape Curvature Extracted from Dynamic Response of A Passing Vehicle”, Mechanical Systems

[18]. Ge, M. \& Lui, E.M, "Structural Damage Identification Using System Dynamic Properties”, Journal Computers and Structures, 83, 2185-2196, 2005

[19]. Sugiono, Mr. of PT. Kereta Api Indonesia (Persero), Surabaya, personal communication, 2013.

[20]. E. L. Wilson, A. Der Kiureghian and E. R. Bayo, "A Replacement for the SRSS Method in Seismic Analysis," Earthquake Engineering and Structural Dynamics,Vol. 9, pp. 187-192, 1981.

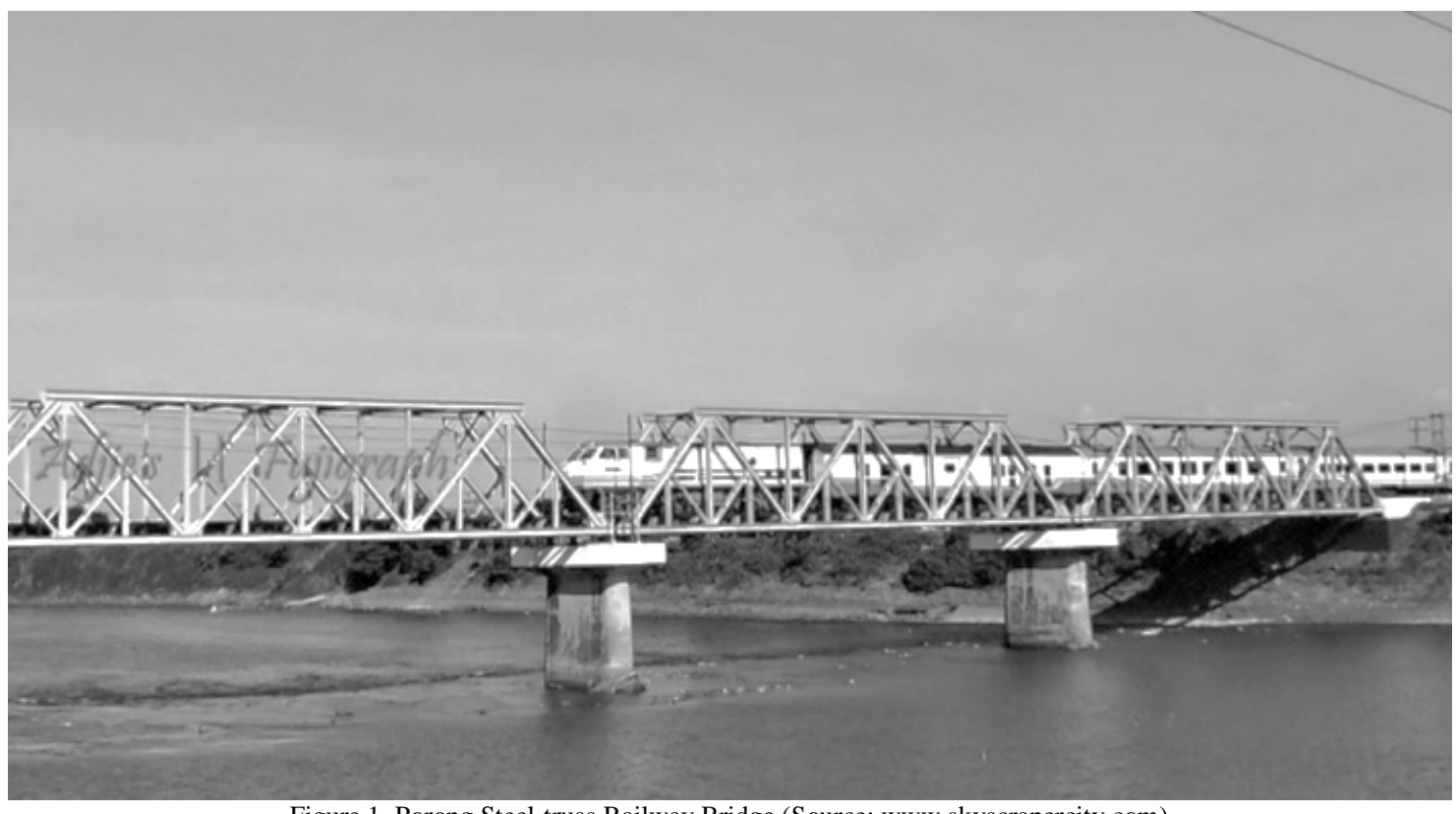

Figure 1. Porong Steel-truss Railway Bridge (Source: www.skyscrapercity.com) 


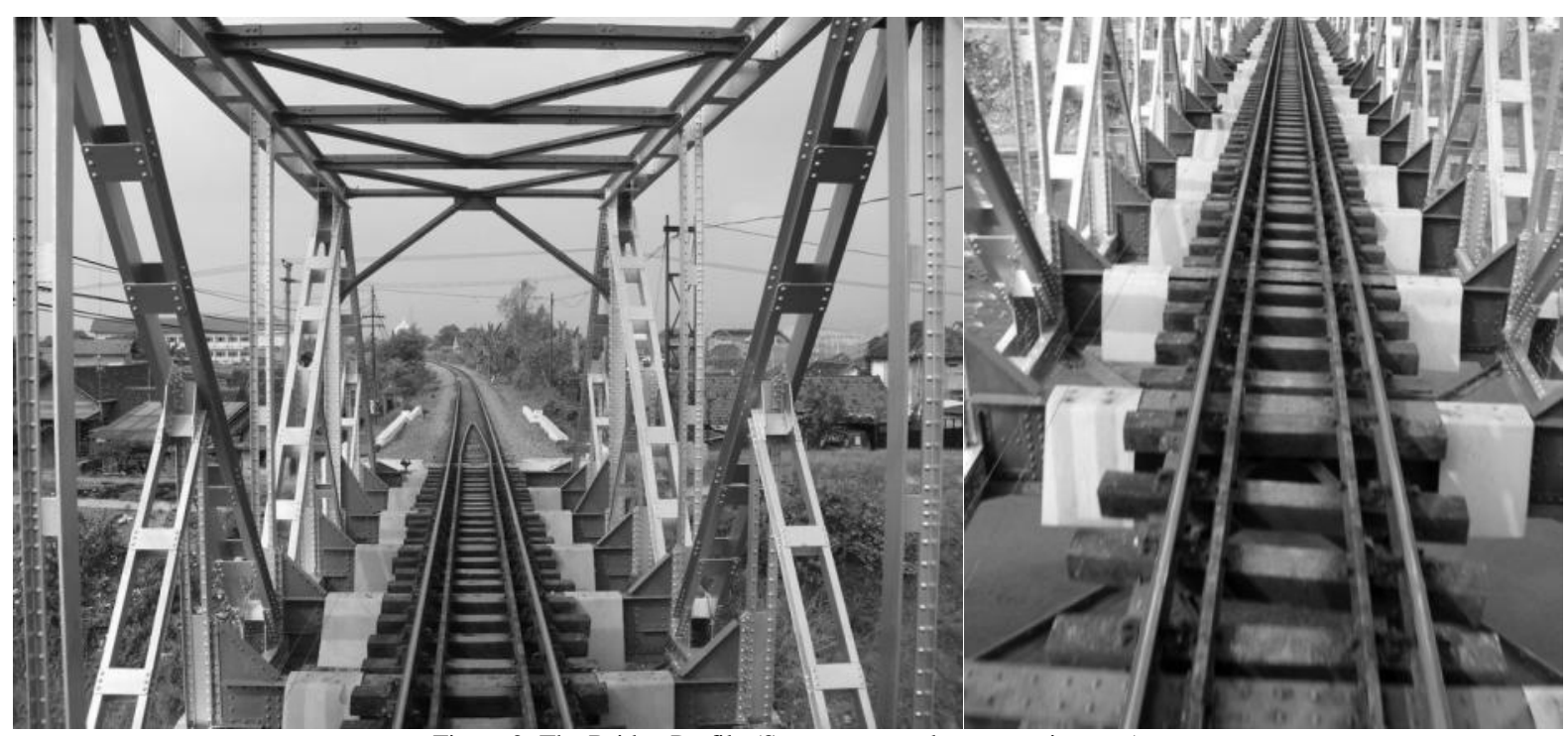

Figure 2. The Bridge Profile (Source: www.skyscrapercity.com)

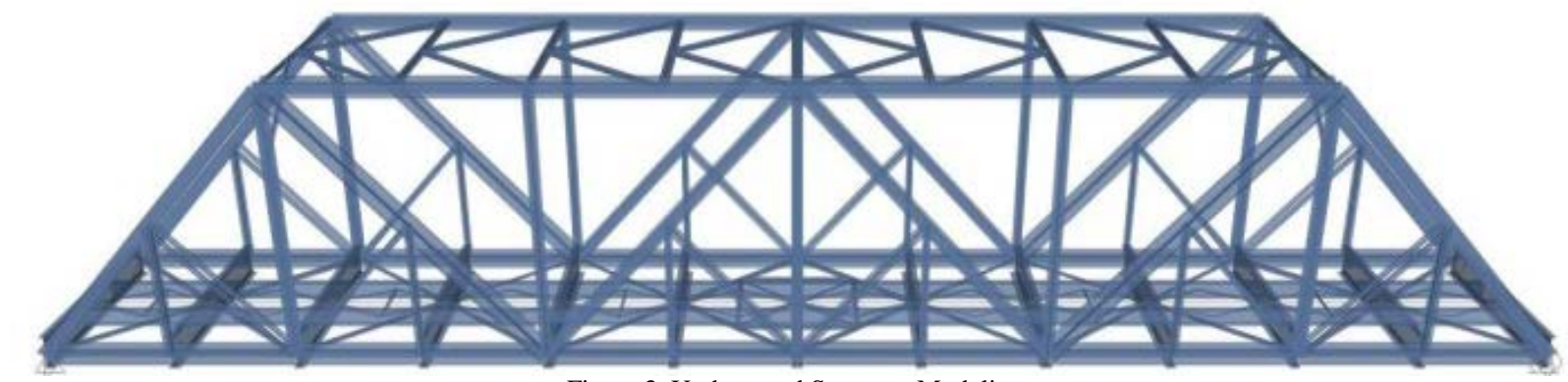

Figure 3. Undamaged Structure Modeling

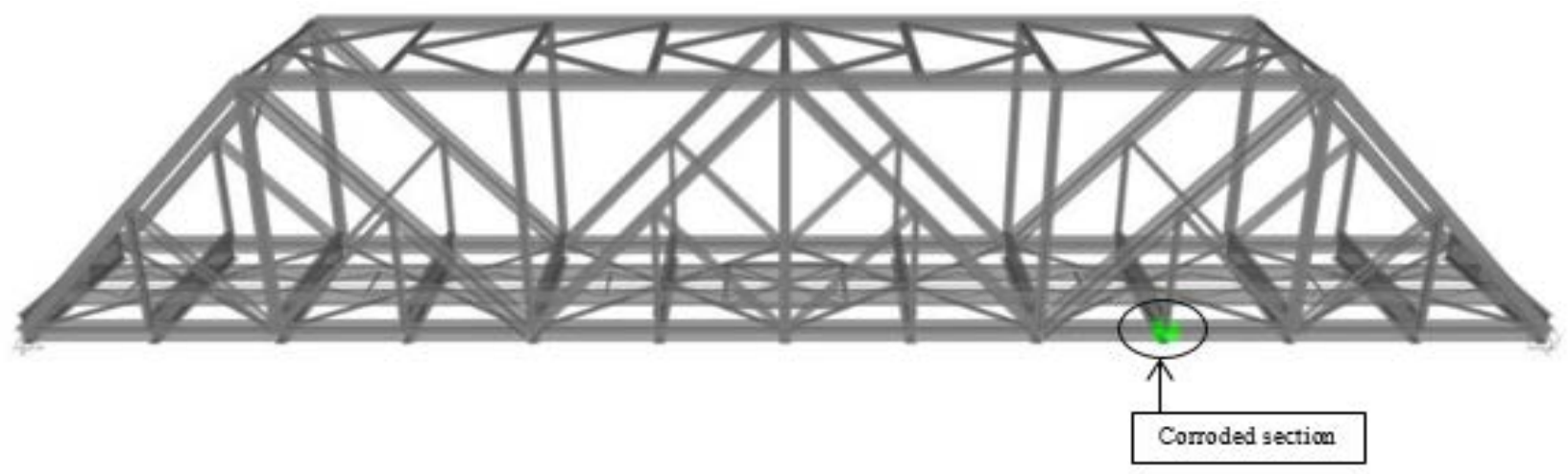

Figure 4. Damaged Structure Modeling

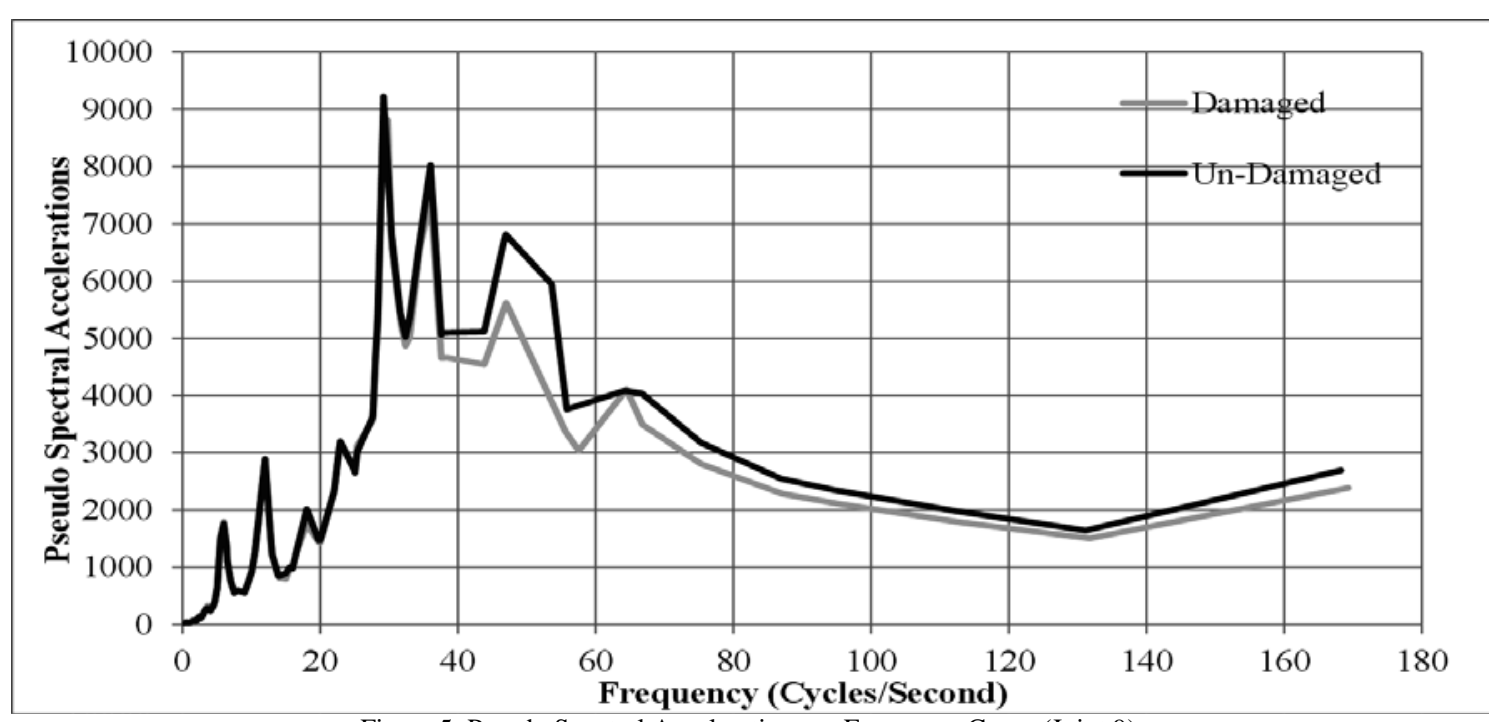

Figure 5. Pseudo Spectral Accelerations vs Frequency Curve (Joint 9) 


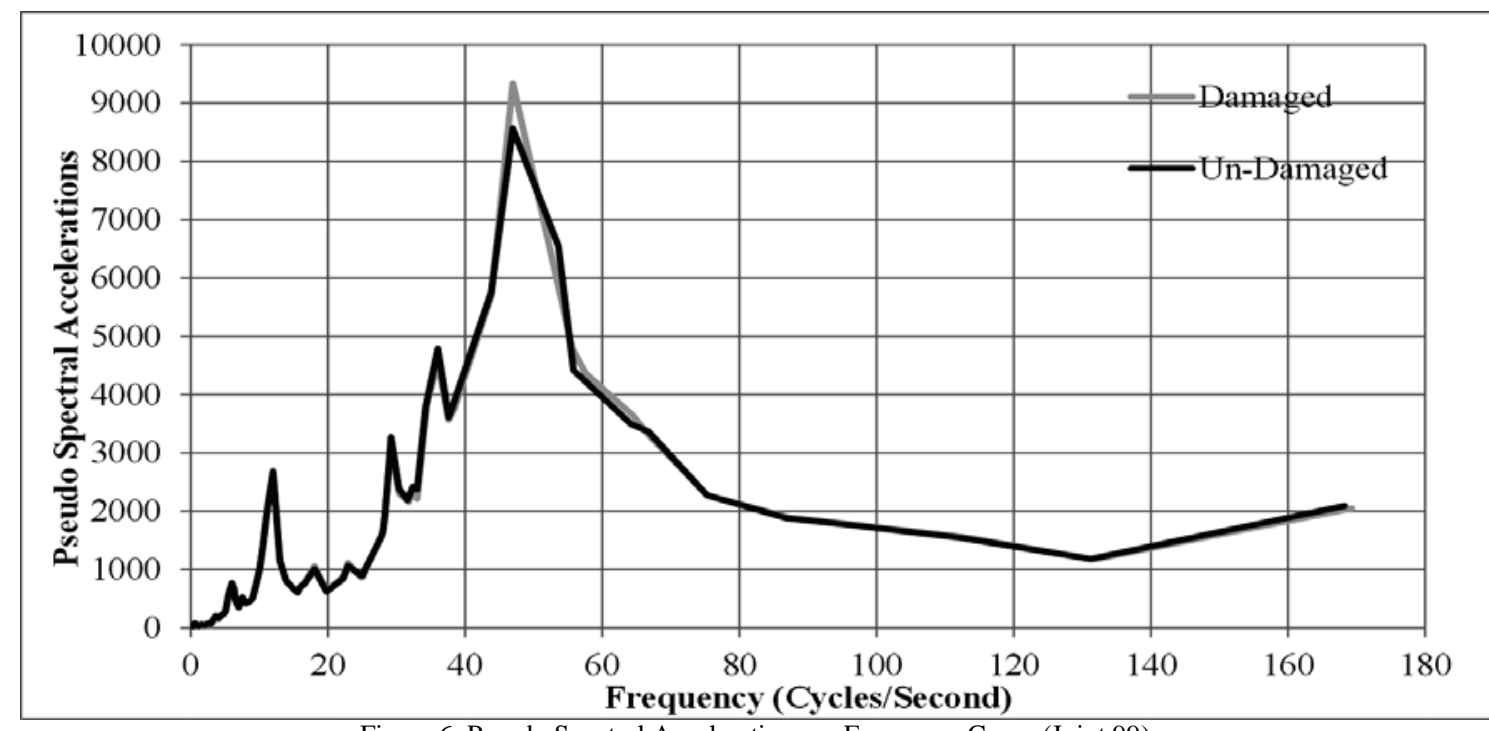

Figure 6. Pseudo Spectral Accelerations vs Frequency Curve (Joint 99)

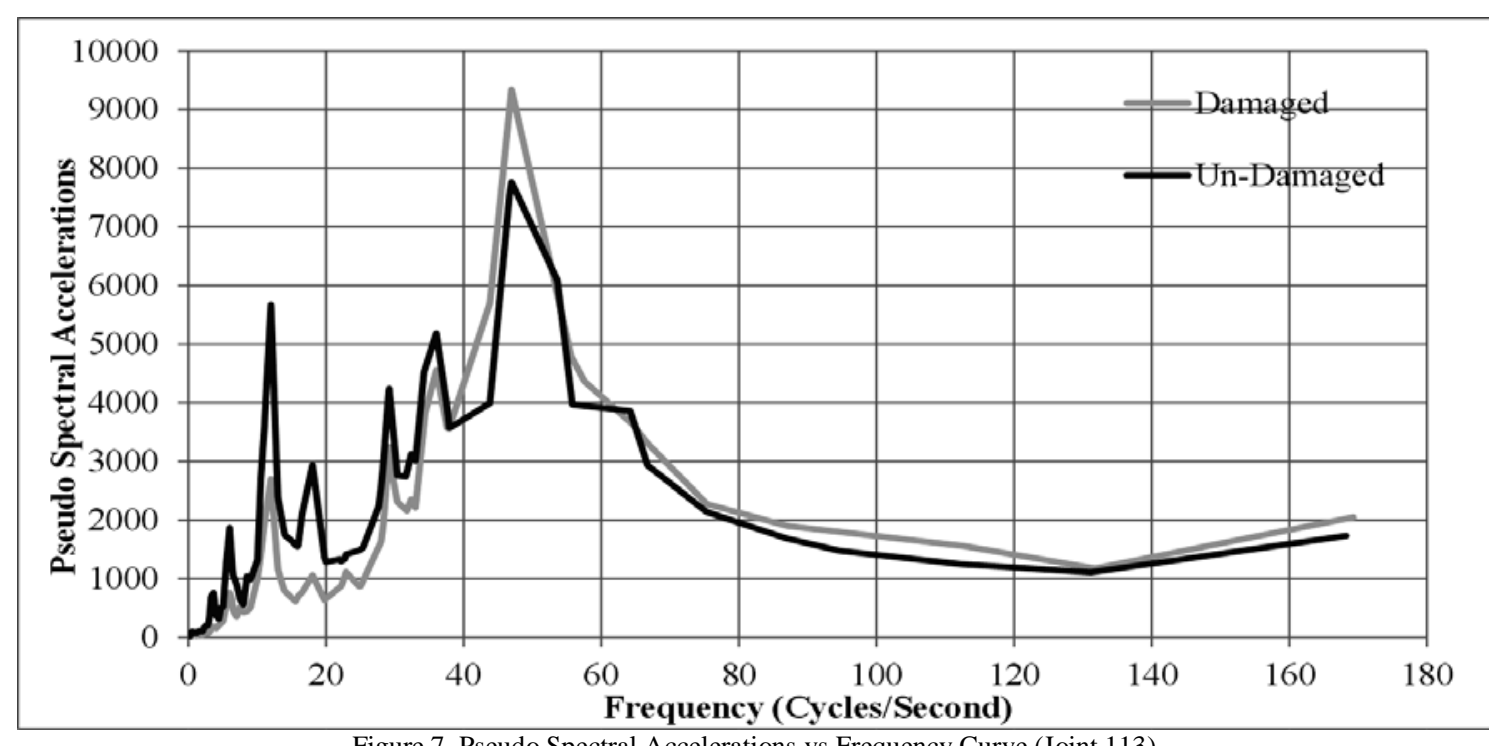

Figure 7. Pseudo Spectral Accelerations vs Frequency Curve (Joint 113)

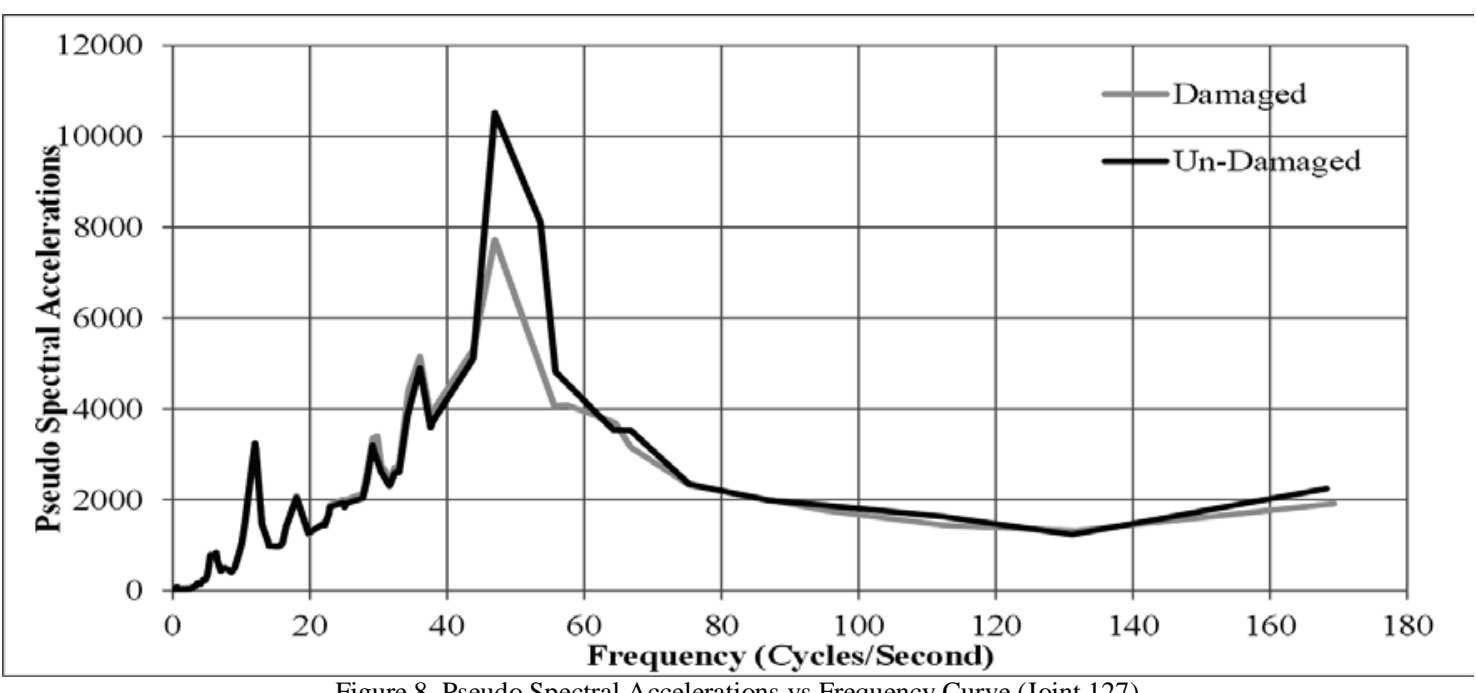

Figure 8. Pseudo Spectral Accelerations vs Frequency Curve (Joint 127) 


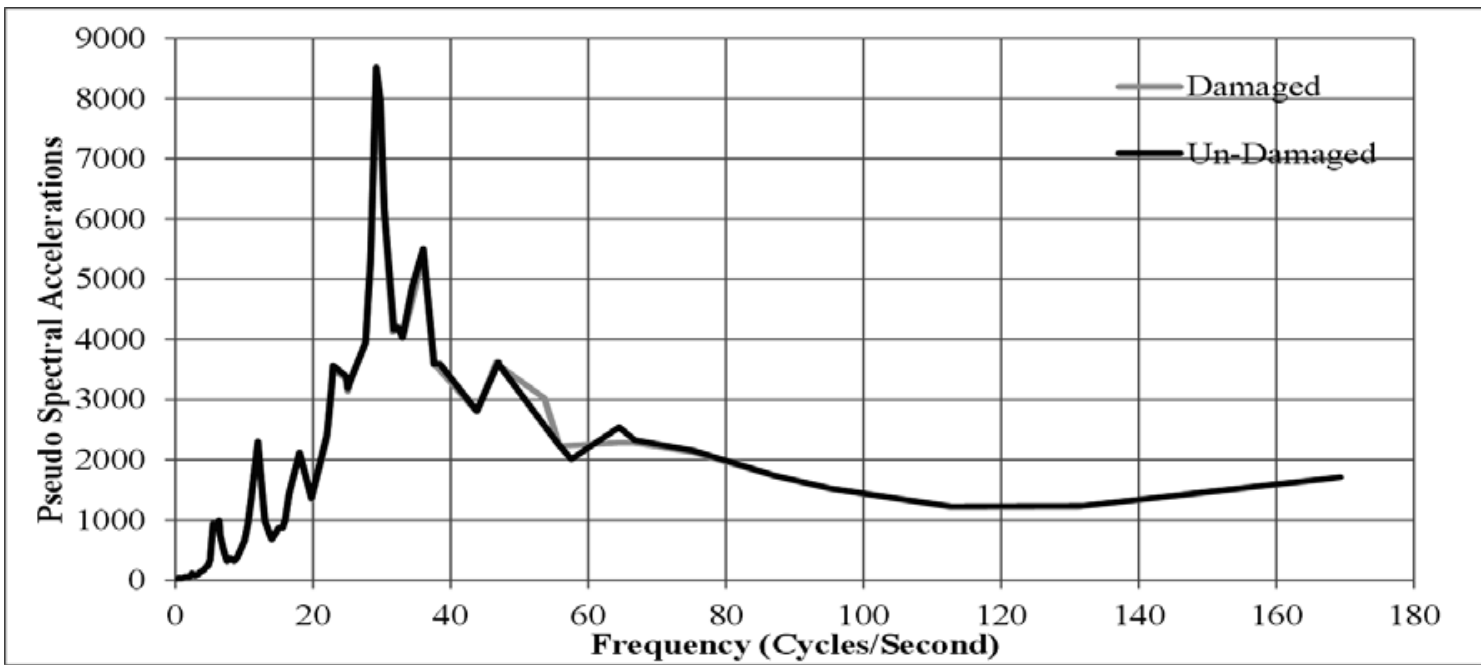

Figure 9. Pseudo Spectral Accelerations vs Frequency Curve (Joint 141)

TABLE 1

STRUCTURAL DAMAGE DETECTION CATEGORIES [2]

\begin{tabular}{|c|c|c|}
\hline Category & & Methodology \\
\hline \multirow{3}{*}{ Modal Parameters } & Natural Frequencies & $\begin{array}{l}\text { - Frequency changes } \\
\text { - Residual force optimization }\end{array}$ \\
\hline & & - Mode shape changes \\
\hline & Mode Shapes & $\begin{array}{l}\text { - Modal strain energy } \\
\text { - Mode shape derivatives }\end{array}$ \\
\hline \multirow[t]{2}{*}{ Matrix Methods } & Stiffness-based & $\begin{array}{l}\text { - Optimization techniques } \\
\text { - Model updating Matrix Methods }\end{array}$ \\
\hline & Flexibility-based & - Dynamically measured flexibility \\
\hline \multirow[b]{2}{*}{ Machine Learning } & Genetic Algorithm & $\begin{array}{l}\text { - Stiffness parameter optimization } \\
\text { - Minimization of the objective function }\end{array}$ \\
\hline & Artificial Neural Network & $\begin{array}{l}\text { - Back propagation network training } \\
\text { - Time delay neural network } \\
\text { - Neural network systems identification with } \\
\text { neural network damage detection }\end{array}$ \\
\hline Other Techniques & & $\begin{array}{l}\text { - Time history analysis } \\
\text { - Evaluation of FRFs }\end{array}$ \\
\hline
\end{tabular}

TABLE 3.

MAX UN-DAMAGED PSA VS MAX DAMAGED NATURAL PSA

\begin{tabular}{lllll}
\hline \multirow{2}{*}{ Joint } & Joint Distance from Middle of Spans & Max Un-damaged PSA & Max Damaged PSA & Deviation \\
\cline { 2 - 5 } & $\mathbf{m}$ & $\mathbf{m m} / \mathbf{s e c} 2$ & $\mathbf{m m} / \mathbf{s e c} 2$ & $\mathbf{\%}$ \\
\hline 9 & 10.44 & $9.22 \mathrm{E}+03$ & $8.88 \mathrm{E}+03$ & $3.76 \%$ \\
99 & 5.22 & $8.57 \mathrm{E}+03$ & $9.33 \mathrm{E}+03$ & $8.97 \%$ \\
113 & 0 & $7.76 \mathrm{E}+03$ & $9.33 \mathrm{E}+03$ & $20.26 \%$ \\
127 & 5.22 & $1.05 \mathrm{E}+04$ & $7.72 \mathrm{E}+03$ & $26.62 \%$ \\
141 & 10.44 & $8.52 \mathrm{E}+03$ & $8.51 \mathrm{E}+03$ & $0.11 \%$ \\
\hline
\end{tabular}


TABLE 2.

UN-DAMAGED NATURAL FREQUENCY AND DAMAGED NATURAL FREQUENCY FOR THE FIRST 50 MODES

\begin{tabular}{|c|c|c|c|}
\hline & Undamaged Frequency & Damaged Frequency & Deviation \\
\hline Mode & $\mathrm{rad} / \mathrm{sec}$ & $\mathrm{rad} / \mathrm{sec}$ & $\%$ \\
\hline 1 & 9.6614 & 9.6615 & $0.0010 \%$ \\
\hline 2 & 18.065 & 18.067 & $0.0111 \%$ \\
\hline 3 & 39.646 & 39.646 & $0.0000 \%$ \\
\hline 4 & 40.085 & 40.085 & $0.0000 \%$ \\
\hline 5 & 40.124 & 40.124 & $0.0000 \%$ \\
\hline 6 & 40.13 & 40.13 & $0.0000 \%$ \\
\hline 7 & 40.373 & 40.373 & $0.0000 \%$ \\
\hline 8 & 40.418 & 40.418 & $0.0000 \%$ \\
\hline 9 & 54.723 & 54.72 & $0.0055 \%$ \\
\hline 10 & 65.967 & 65.966 & $0.0015 \%$ \\
\hline 11 & 75.924 & 75.919 & $0.0066 \%$ \\
\hline 12 & 87.175 & 87.177 & $0.0023 \%$ \\
\hline 13 & 97.694 & 97.694 & $0.0000 \%$ \\
\hline 14 & 99.648 & 99.648 & $0.0000 \%$ \\
\hline 15 & 100.15 & 100.15 & $0.0000 \%$ \\
\hline 16 & 100.31 & 100.31 & $0.0000 \%$ \\
\hline 17 & 124.18 & 124.19 & $0.0081 \%$ \\
\hline 18 & 139.2 & 139.16 & $0.0287 \%$ \\
\hline 19 & 142.78 & 142.77 & $0.0070 \%$ \\
\hline 20 & 143.86 & 143.86 & $0.0000 \%$ \\
\hline 21 & 155.88 & 155.87 & $0.0064 \%$ \\
\hline 22 & 159.27 & 159.27 & $0.0000 \%$ \\
\hline 23 & 173.44 & 173.43 & $0.0058 \%$ \\
\hline 24 & 173.71 & 173.71 & $0.0000 \%$ \\
\hline 25 & 178.09 & 178.09 & $0.0000 \%$ \\
\hline 26 & 182.8 & 183.46 & $0.3611 \%$ \\
\hline 27 & 183.46 & 187.3 & $2.0931 \%$ \\
\hline 28 & 190.73 & 190.73 & $0.0000 \%$ \\
\hline 29 & 198.58 & 199.36 & $0.3928 \%$ \\
\hline 30 & 203.53 & 203.54 & $0.0049 \%$ \\
\hline \multirow{2}{*}{ Mode } & Undamaged Frequency & Damaged Frequency & Deviation \\
\hline & $\mathrm{rad} / \mathrm{sec}$ & $\mathrm{rad} / \mathrm{sec}$ & $\%$ \\
\hline 31 & 214.88 & 216.11 & $0.5724 \%$ \\
\hline 32 & 226.25 & 226.25 & $0.0000 \%$ \\
\hline 33 & 236.21 & 236.21 & $0.0000 \%$ \\
\hline 34 & 238.36 & 241.36 & $1.2586 \%$ \\
\hline 35 & 275.28 & 275.28 & $0.0000 \%$ \\
\hline 36 & 293.15 & 294.9 & $0.5970 \%$ \\
\hline 37 & 294.91 & 295.28 & $0.1255 \%$ \\
\hline 38 & 336.95 & 349.49 & $3.7216 \%$ \\
\hline 39 & 350.42 & 361.34 & $3.1163 \%$ \\
\hline 40 & 403.33 & 405.06 & $0.4289 \%$ \\
\hline 41 & 419.04 & 419.33 & $0.0692 \%$ \\
\hline 42 & 472.94 & 473.27 & $0.0698 \%$ \\
\hline 43 & 546.02 & 547.2 & $0.2161 \%$ \\
\hline 44 & 594.6 & 598.64 & $0.6794 \%$ \\
\hline 45 & 705.67 & 708.51 & $0.4025 \%$ \\
\hline 46 & 823.89 & 827.95 & $0.4928 \%$ \\
\hline 47 & 1057 & 1063.7 & $0.6339 \%$ \\
\hline 48 & 1457.5 & 1463.1 & $0.3842 \%$ \\
\hline 49 & 2539.3 & 2535.8 & $0.1378 \%$ \\
\hline 50 & 25341 & 26213 & $3.4411 \%$ \\
\hline
\end{tabular}

